\title{
To study the relevance of inpatient dermatology referrals in a Teaching Hospital of North India
}

\author{
Parul Chojer, Suresh K. Malhotra, Ashwant Kaur
}

Department of Dermatology, Venereology and Leprology, Government Medical College, Amritsar, India

Corresponding author: Dr. Suresh K. Malhotra, E-mail: dskm50@gmail.com

\begin{abstract}
Background: Dermatology is primarily considered to be an outpatient-centered specialty. However, several inpatient admissions to other specialties require dermatologic consultation for optimum management. Aims: The aim of this study was to evaluate the pattern of referrals sent to the dermatology department by other Departments and impact of dermatology consultation on patient management. Materials and Methods: The study included all inpatients referred to dermatology department of a tertiary care centre of North India during a two year period. The demographic details, specialties requesting consultation, cause of referral, and dermatological advice have been recorded and analyzed. Results: Dermatology consultation changed the dermatologic diagnosis and treatment. General medicine requested the maximum number of referrals, skin rash being the most common cause for referral. Accurate diagnosis on referrals was provided by only $25.23 \%$ of non dermatologists. Common dermatological disorders were often misdiagnosed by these physicians, and dermatology referrals had significant impact on the diagnosis and subsequent management of these patients. Conclusion: While dermatologic referral leads to improved patient care, there is a need for better training of non dermatologists enabling them to recognize and treat common dermatoses.
\end{abstract}

Key words: Dermatology; Inpatient; Referral

\section{INTRODUCTION}

Dermatology practice takes place mainly in the outpatient setting. However, several inpatient referrals are made to dermatology departments by other specialties on a daily basis for proper patient management in the hospital settings [1]. The knowledge of dermatology among non-dermatologists is believed to be very poor [2-5]. Patients admitted to non-dermatology units may often have numerous skin lesions besides the systemic disease for which they are hospitalized $[5,6]$. The dermatoses may be associated with significant morbidity and at times mortality [7]. These inpatients with dermatoses often require expert dermatology consultation. The interdepartmental referral not only helps in patient care but also improves the diagnostic acumen and clinical knowledge of the clinician [6,7-11].

\section{MATERIALS AND METHODS}

This retrospective observational study, after obtaining approval from Institutional Ethics Committee, was carried out at tertiary hospital in North India assessing data over a period of 2 years. The Department of Dermatology at the hospital is responsible for all dermatological consultations for inpatients.

The data thus obtained has been statistically analyzed with respect to patient demography, frequency of referrals made by different specialties, causes of referrals (presumptive diagnoses made by non dermatologists), diagnostic accuracy of referring departments by comparing with the final dermatological diagnoses made by senior faculty members as the gold standard, and impact of dermatology consultations on the management.

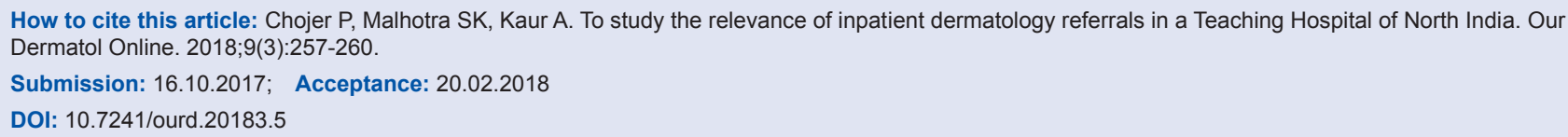


Specific investigations such as $\mathrm{KOH}$ examination, Gram's smear, Tzanck smear, slit skin smear, skin biopsy, and blood and radiological investigations were undertaken in selected cases, wherever deemed appropriate to substantiate the clinical diagnosis. All the patients were examined within 24 hours of request for referral.

\section{RESULTS}

During 2 year period, total of 817 referrals were received. Mean age of our patients was 35.95 (range- 1 day to 85 years) (Fig. 1). $82.7 \%$ of dermatological consultations were sought for patients $>20$ years. There were 360 males (44.1\%) and 457 females (55.9\%), with a M: F ratio - 1:1.269. Majority of patients were in age group 21 - 40 years (48.5\%). Referral was most frequently sought by department of Internal Medicine, 339 patients(41.5\%), followed by department of Obs \& Gynae, 231 patients (28.3\%), Pediatrics 73 patients $(8.9 \%)$, department of Surgery 63 patients $(7.7 \%)$ and Orthopaedics 52 patients (6.4\%) (Table 1).

Unspecified "skin rash" was the most common dermatologic condition, for which skin referral was sought (335 cases $41 \%$ ) followed by skin infections (145 cases $17.7 \%)$, vesiculobullous disorders $(8.4 \%)$, drug rash $(7 \%)$, oral and genital lesions and eczema $(2.7 \%)$. All these diagnoses were made by the referring departments and mentioned on the referral sheets. The different conditions for which referrals were sought are tabulated in Table 2.

The different diagnoses were made by the dermatologists after examining the referred patients. Cutaneous infection and infestations were the most commonly diagnosed condition (55.3\%), which included parasitic infections, 163 cases (20\%), fungal infections, 142 cases (17.4\%), viral infections, 126 cases

Table 1 Specialities requiring dermatological consultation

\begin{tabular}{lcc}
\hline Department & $\begin{array}{c}\text { Number of } \\
\text { patients }\end{array}$ & $\begin{array}{c}\text { Percentage of } \\
\text { patients }\end{array}$ \\
\hline Internal medicine & 339 & 41.5 \\
Gynaecology & 231 & 28.3 \\
Paediatrics & 73 & 8.9 \\
General surgery & 63 & 7.7 \\
Orthopaedics & 52 & 6.4 \\
Chest \& tuberculosis & 29 & 3.5 \\
Psychiatry & 25 & 3.1 \\
ENT & 2 & 0.2 \\
Plastic surgery & 2 & 0.2 \\
Cardiology & 1 & 0.1 \\
\hline
\end{tabular}

$(15.4 \%)$ and bacterial infections, 21 cases $(2.6 \%)$ (Fig. 2). Most of the cases of bacterial and fungal infections were referred from medicine department, however maximum cases of viral infections were from gynaecology department. This was followed by eczema, 112 cases $(13.7 \%)$, drug reactions, 93 cases $(10.2 \%)$, out of which 10 cases were of severe adverse drug reactions. Other dermatological diagnosis which were made are tabulated in Table 3. Dermatology consultation resulted in revised diagnosis in about $75 \%$ of instances of case referrals. (Fig. 3)

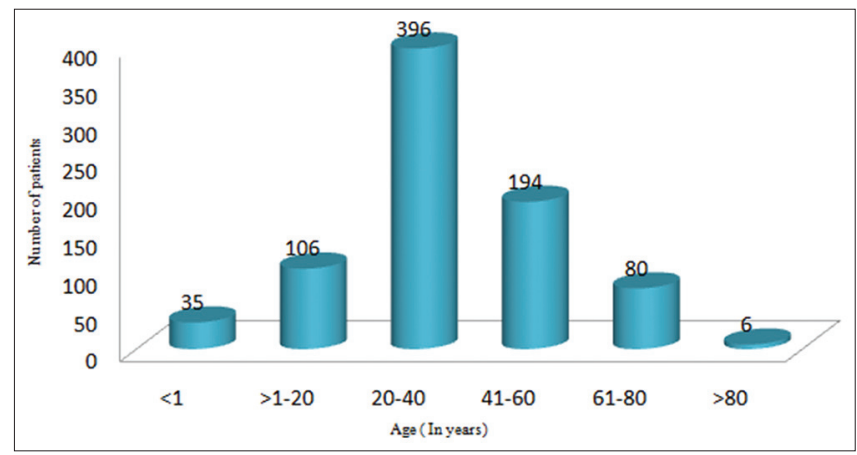

Figure 1: Age distribution of the study.

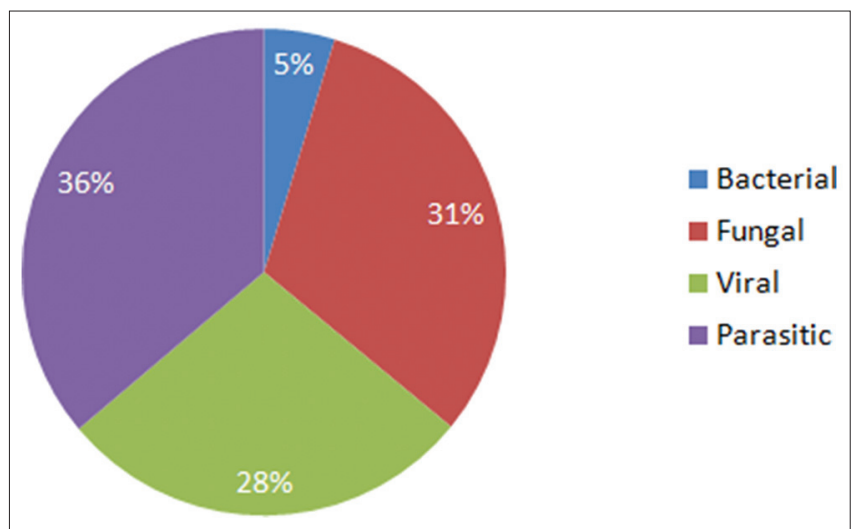

Figure 2: Cutaneous infections and infestations.

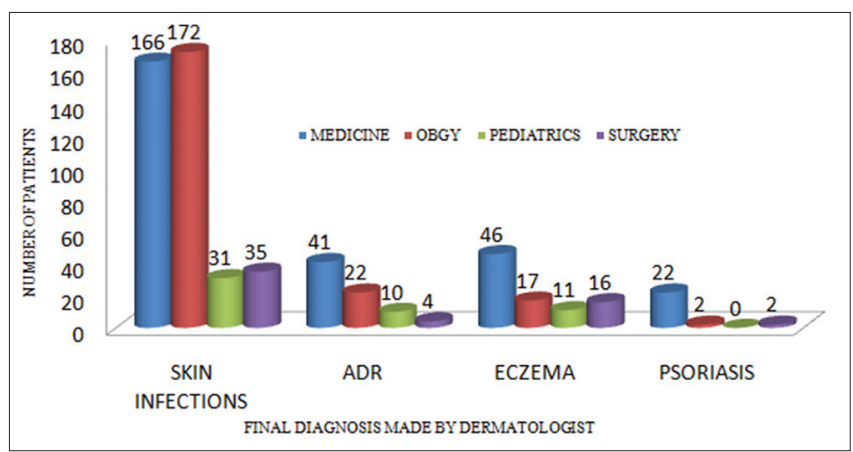

Figure 3: Final diagnosis made by dermatologist. 
Table 2 Dermatological diagnoses by the referring departments

\begin{tabular}{lcc}
\hline Provisional diagnosis & $\begin{array}{c}\text { Number of } \\
\text { patients }\end{array}$ & $\begin{array}{c}\text { Percentage of } \\
\text { patients }\end{array}$ \\
\hline Skin rash & 335 & 41 \\
Skin infection & 145 & 17.7 \\
Vesiculobullous disorders & 69 & 8.4 \\
Drug rash & 57 & 7.0 \\
Oral/Perioral lesions & 49 & 6.0 \\
Pigmentary disorders & 33 & 4.0 \\
Non specific skin lesions & 30 & 3.7 \\
Genital lesions & 27 & 3.3 \\
Eczema & 22 & 2.7 \\
Skin ulcers & 16 & 2.0 \\
Skin swelling & 8 & 1.0 \\
Nail lesions & 7 & 0.9 \\
Purpuric rash/Vasculitis & 7 & 0.9 \\
Ischemic lesions & 5 & 0.6 \\
Connective tissue & 4 & 0.5 \\
disorders & & \\
Psoriasis & 3 & 0.4 \\
\hline
\end{tabular}

Table 3 Final diagnosis made by dermatologist

\begin{tabular}{lcc}
\hline Diagnosis & $\begin{array}{c}\text { Number of } \\
\text { patients }\end{array}$ & $\begin{array}{c}\text { Percentage of } \\
\text { patients }\end{array}$ \\
\hline Cutaneous infections : & 21 & 2.6 \\
Bacterial infections & 142 & 17.3 \\
Fungal infections & 126 & 15.4 \\
Viral infections & 163 & 20.0 \\
Parasitic infestations & 112 & \\
& & 13.7 \\
Eczema/dermatitis & 83 & \\
& & 10.2 \\
Cutaneous adverse drug & 10 & \\
reaction (non severe type): & & 1.2 \\
Severe adverse drug & 32 & \\
reaction: & 19 & 3.9 \\
Psoriasis & 13 & 2.3 \\
Connective tissue disorder & 11 & 1.6 \\
Leg ulcers & 11 & 1.3 \\
Urticaria/angioedema & 9 & 1.3 \\
Genodermatoses & 9 & 1.1 \\
Vasculitis & 9 & 1.1 \\
Diabetic dermopathy & 9 & 1.1 \\
Immunobullous disorders & & 1.1 \\
Disorders of sweat and & 5 & 0.6 \\
sebaceous glands & 33 & 4.0 \\
Vitiligo & & \\
Miscellaneous : & &
\end{tabular}

\section{DISCUSSION}

In this study, we analysed 817 patients referred from various departments for dermatological consultation. In our study, most of the dermatology consultations were sought for patients $>20$ years $(82.7 \%)$. In most of previously published works [12], males have outnumbered females while our study constituted $55.9 \%$ females. In the present study, internal medicine accounted for the highest proportion of dermatological consultations (41.5\%). Internal medicine has been shown to send maximum dermatology referrals in most of the literature $[12,13]$; thus corroborating our findings. This might have occurred as many medical disorders are associated with dermatological manifestations which may serve as important clues for diagnosis of the underlying medical conditions. However, in some studies [11,14,15], neurology unit has accounted for a significant number of referrals after internal medicine. In an Indian study [3], from Secunderabad, surgery $(29.8 \%)$ and internal medicine (29.7\%) departments were responsible for more than half of the referrals to dermatologists.

Non specific skin rash constituted most of the dermatology referrals, $41 \%$, followed by cutaneous infections in $17.7 \%$. A similar finding was obtained by Walia and Deb [3] in India. However, in final diagnosis made by dermatologist, cutaneous infections and infestations accounted for $55.3 \%$ followed by eczema and adverse drug reactions in 13.7 and $10.2 \%$ patients respectively. Whereas, maximal referrals from various departments were sent for non specific skin rash i.e., $41 \%$, cutaneous infections and eczema/dermatitis in $17.7 \%$ and $2.7 \%$ respectively. Most of the patients with tentative diagnosis of skin rash, after dermatology consultation came out to be of cutaneous infections. $13.7 \%$ patients had eczema/dermatitis in reality, however provisional diagnosis of eczema was kept in only $2.7 \%$ patients, suggesting its underdiagnosis by non dermatologists.

We found that nondermatologists could provide an accurate dermatological diagnosis only in $25.23 \%$ of cases. This rate is similar to another study from the USA [12], where the diagnostic accuracy was reported to be only $23.9 \%$ and lower when compared to another Indian study (39\%) [13]. However, this figure is quite low when compared to $48 \%$ diagnostic accuracy in a study conducted by Falanga et al. [9].

This study also showed the inability of many non dermatologists to recognize simple cutaneous infections such as scabies and drug reactions. Dermatology is primarily a visual discipline. Most dermatoses can easily be diagnosed by a trained eye without expensive investigations that are often advised by non dermatologists. Non dermatologists usually tend to use combined topical preparations often containing steroids. This has led to modification of the original clinical picture, thus making subsequent accurate diagnosis difficult even by a trained dermatologist, as is commonly seen with topical steroid 
abuse. Frequent inter-departmental referrals and interactive inter-departmental teaching and training programmes are essential, thus providing exposure to non dermatology residents regarding diagnosing and managing common dermatoses.

\section{Statement of Human and Animal Rights}

All procedures followed were in accordance with the ethical standards of the responsible committee on human experimentation (institutional and national) and with the Helsinki Declaration of 1975, as revised in 2008.

\section{Statement of Informed Consent}

Informed consent was obtained from all patients for being included in the study.

\section{REFERENCES}

1. Storan ER, McEvoy MT, Wetter DA, el-Azhary RA, Camilleri MJ, Bridges AG, et al. Experience of a year of adult hospital dermatology consultations. Int J Dermatol 2015;54:1150-6.

2. Chowdhury SN, Podder I, Saha A, Bandyopadhyay D. Interdepartmental dermatology: Characteristics and impact of dermatology inpatient referrals at a teaching hospital in Eastern India. Indian J Dermatol 2017;62:29-32.

3. Walia NS, Deb S. Dermatology referrals in the hospital setting. Indian J Dermatol Venereol Leprol. 2004;70:285-7.

4. Maza A, Berbis J, Gaudy-Marqueste C, Morand JJ, Berbis P, Grob JJ, et al. Evaluation of dermatology consultations in a prospective multicenter study involving a French teaching hospital. Ann
Dermatol Venereol. 2009;136:241-8.

5. Fernandes IC, Velho G, Selores M. Dermatology inpatient consultation in a Portuguese university hospital. Dermatol Online J. 2012;18:16.

6. Itin PH. Dermatologic Consultations in the Hospital Ward: The Skin, an Interdisciplinary Organ. Dermatology. 2009;219:193-4.

7. Tay LK, Lee HY, Thirumoothy T, Pang SM. Dermatology referrals in an East Asian tertiary hospital: A need for inpatient medical dermatology. Clin Exp Dermatol. 2011;36:129-34.

8. Lorente-Lavirgen AI, Bernabeu-Wittel J, Pulpillo-Ruiz A, de la Torre-García JM, Conejo-Mir J. Inpatient Dermatology Consultation in a Spanish Tertiary Care Hospital: A Prospective Cohort Study. Actas Dermosifiliogr. 2013;104:148-55.

9. Falanga V, Schachner LA, Rae V, Ceballos PI, González A, Liang G, et al. Dermatologic consultations in the hospital setting. Arch Dermatol. 1994;130:1022-5.

10. Balai M, Gupta LK, Khare AK, Mittal A, Mehta S, Bharti G. Pattern of inpatient referrals to dermatology at a tertiary care centre of South Rajasthan. Indian Dermatol Online J. 2017;8:25-8.

11. Fischer M, Bergert H, Marsch WC. The dermatologic consultation. Hautarzt. 2004;55:543-8.

12. Davila M, Christenson LJ, Sontheimer RD. Epidemiology and outcomes of dermatology in-patient consultations in a Midwestern U.S. university hospital. Dermatol Online J. 2010;16:12.

13. Chandalavada M. Study of Inpatient Dermatologic Referrals. Abstract: 12 $2^{\text {th }}$ South Zone Conference of IADVL; October, 2012. p. 102.

14. Mancusi S, CyroFesta N. Inpatient dermatological consultation in university hospital. Clinics. 2010;65:851-5.

15. Penate Y, Guillermo N, Melwani P, Martel R, Borrego L. Dermatologists in Hospital Wards: An 8-year Study of Dermatology Consultation. Dermatology. 2009;219:225-31.

Copyright by Parul Chojer, et al. This is an open-access article distributed under the terms of the Creative Commons Attribution License, which permits unrestricted use, distribution, and reproduction in any medium, provided the original author and source are credited.

Source of Support: Nil, Conflict of Interest: None declared. 